\title{
Balloon leakage dilation over arterio-aorta rail support greatly facilitates a complex aortic paravalvular leak closure
}

\author{
Eustaquio Maria Onorato ${ }^{1}$, Massimo Carasi ${ }^{2}$, Mirko Zadro $^{2}$, Umberto Cucchini ${ }^{2}$, Fabio Chirillo ${ }^{2}$ \\ ${ }^{1}$ Centro Cardiologico Monzino, Istituto di Ricovero e Cura a Carattere Scientifico (IRCCS), University School of Milan, Milan, Italy \\ ${ }^{2}$ UOC Cardiologia, Ospedale di Bassano del Grappa, Azienda Sanitaria ULSS 7 Pedemontana, Bassano del Grappa, Italy
}

Adv Interv Cardiol 2021; 17, 2 (64): 223-225

DOI: https://doi.org/10.5114/aic.2021.107505

In patients with an aortic paravalvular leak (PVL), the retrograde femoral arterial approach is most commonly used [1, 2]. Nevertheless, in some cases an antegrade (via trans-septal puncture) or a retrograde transapical approach may be alternative options [3]. Particularly for the anatomically hard-to-approach calcified serpiginous tracts where an extra support is needed, an arterio-arterial loop can be established and may be key for a successful procedure [4].

A 75-year-old male with previous ischaemic stroke, paroxysmal atrial fibrillation, and multiple previous percutaneous coronary interventions was admitted for congestive heart failure (NYHA class III). He had a history of surgical removal of subaortic membrane and right coronary leaflet plasty, followed 20 years later by mechanical aortic valve replacement and woven fabric ascending aortic surgical graft. Transthoracic echocardiography (TTE) and transoesophageal echocardiography (TEE) showed dilatation of left ventricle (LV) with an ejection fraction of $45 \%$, and confirmed the presence of a calcified oval-shaped $6 \times 5 \mathrm{~mm}$ PVL located underneath the left coronary sinus.

The patient denied a redo surgery and after heart team discussion a transcatheter PVL closure was planned. An informed consent form was signed by the patient. The procedure was performed under TEE and fluoroscopic guidance using general anaesthesia. Right femoral artery puncture was performed, and a severe paravalvular aortic regurgitation was also demonstrated by aortography (Figure $1 \mathrm{~A}$ ). With the support of a 4-Fr Amplatz left catheter (AL2) we easily passed a hydrophilic Terumo 0.35 inch guide wire retrograde from the aorta to the LV through the calcific serpiginous PVL; however, none of the catheters used (AL2- 4Fr, Judkins right 5-Fr, Multipurpose 5-Fr, Glide- cath 4-Fr) could be advanced through the leak over the hydrophilic wire. It was decided to re-advance the hydrophilic guidewire, establishing a loop in the left ventricle, and then re-direct it across the mechanical prosthetic leaflets and place it finally into the descending aorta (Figure $2 \mathrm{~A}$ ). A Glidecath 4-Fr was subsequently advanced over the hydrophilic wire that was replaced by 0.035 -inch wire, $260 \mathrm{~cm}$ in lenght super stiff guidewire (Boston Scientific), thus creating an arterio-aorta rail, without the need to externalize the wire through an additional radial access. Over the exchange wire a $4.0 \mathrm{~mm}$ PTA balloon dilatation catheter was placed across the leakage and dilated twice, not beyond its rated burst pressure, taking care to keep in place the arterio-aorta rail (Figure $2 \mathrm{~B}$ ). The stronger support finally allowed progression of the retrograde 7 -Fr delivery sheath into the LV. A specifically designed, $7 \mathrm{~mm}$ square twist PLD device (PLD, Occlutech, Helsingborg, Sweden) was successfully deployed (Figures 2 C, D) and the final echocardiographic and angiographic control confirmed the effective PVL closure (Figure 1 B). The postoperative course was uneventful, and the patient was discharged on the third post-operative day. TTE confirmed stable position of the device with trivial residual leak.

In conclusion, the balloon leakage dilation over an arterio-aorta rail strong support allowed us to get across the anatomically hard-to-approach calcified serpiginous leak with the 7-FR delivery sheath and successfully accomplish the procedure.

\section{Conflict of interest}

Eustaquio Maria Onorato is a consultant for Occlutech, manufacturer of the device. The remaining authors declare no confict of interest. 

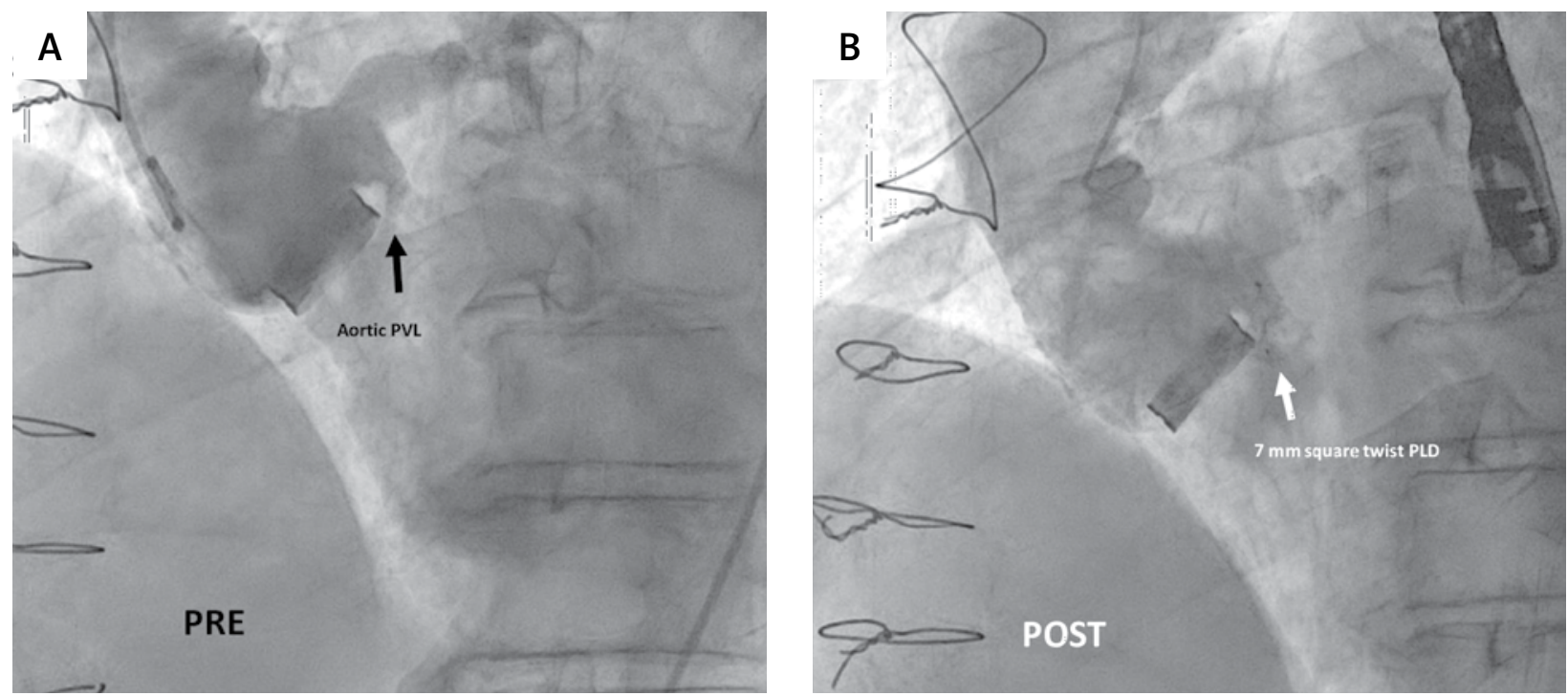

Figure 1. A - Baseline aortic angiogram showing the regurgitant jet through the calcific serpiginous aortic paravalvular leak (black arrow); B - post-procedure aortography with the device in situ (white arrow) showing mild regurgitant jet
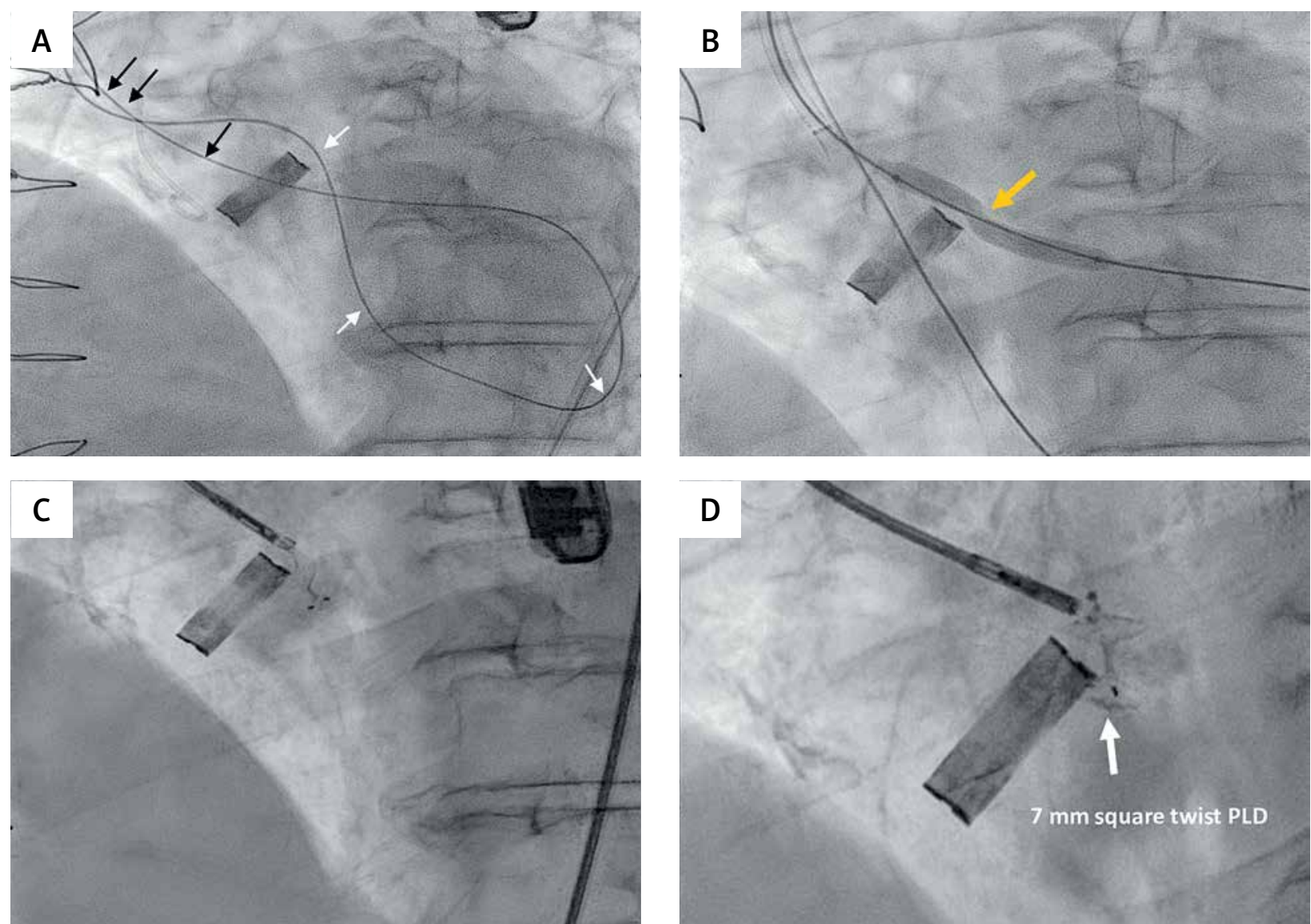

Figure 2. Procedural steps showing retrograde aortic paravalvular leak crossing and closure thanks to a modified technique. A - The hydrophilic guidewire from the aorta crossed retrogradely the serpiginous leak and after forming a big loop in the left ventricle (white arrows) was advanced across the mechanical prosthetic leaflets into the aorta (black arrows), establishing an arterio-aorta rail; $\mathbf{B}$ - the hydrophilic wire has been replaced by a super stiff exchange guidewire, and over it a $4.0 \mathrm{~mm}$ PTA balloon dilatation catheter was placed across the leakage and dilated (orange arrow); C, D - after 7-Fr delivery sheath progression into the LV, a $7 \mathrm{~mm}$ square twist PLD (white arrow) was correctly deployed 


\section{References}

1. Calvert PA, Northridge DB, Malik IS, et al. Percutaneous device closure of paravalvular leak. Combined experience from the United Kingdom and Ireland. Circulation 2016; 134: 934-44.

2. Cruz-Gonzalez I, Rama-Merchan JC, Rodriguez-Collado J, et al. Transcatheter closure of paravalvular leaks: state of the art. Neth Heart J 2017; 25: 116-24.

3. Damluj AA, Kaynak HE, Heldman AW. Combined retrograde/antegrade approach to transcatheter closure of an aortic paravalvular leak. Tex Heart Inst J 2015; 42: 443-7.

4. Jiménez-Brítez G, Panaro A, Maldonado G, et al. Use of radial access to create an arterio-arterial loop to facilitate the percutaneous closure of paravalvular aortic leak. Is it feasible? REC Interv Cardiol 2020; 2: 228-31. 